\title{
A Principal Component Approach to Measuring Investor Sentiment in Hong Kong
}

\author{
Terence Tai-Leung Chong *
}

\author{
Bingqing $\mathrm{Cao}^{\dagger}$
}

\author{
Wing Keung Wong $\ddagger$
}

\begin{abstract}
In light of the increasing integration between China and Hong Kong, this paper develops a new market sentiment index for the Hong Kong stock market, one of the largest stock market in the world. The components of the sentiment measure includes the turnover ratio, short-selling volume, money flow, HIBOR and return of the U.S. and Japanese markets. We also include the Shanghai and Shenzhen Composite index in our measure to capture the influence of Chinese markets on the Hong Kong market. A threshold regression model using the sentiment index as a threshold variable is estimated to capture the state of the Hong Kong stock market. The result of Hansen (2000) likelihood ratio test divides Hong Kong's stock market into three regimes. It is shown that when our sentiment index is above (below) the upper (lower) threshold, the HSI generally moves upward (downward). We also show that the trading rule which shorts (longs) the HSI or SEP/HKEx LargeCapIndex when the sentiment index is above (below) the upper threshold value can beat the buy-and-hold strategy.
\end{abstract}

Keywords: Principal component analysis; market sentiment; CSI 300; threshold model.

\section{Introduction}

Over the past two decades, there has been an increasing interest in the study of investor sentiment. C. Lee, Shleifer, and Thaler (1991) find that reductions of closed-end funds can be used as an indicator for shifts in individual trader sentiment. Neal and Wheatley (1998) find a positive relationship between expected returns of small firms and fund discounts, while no correlation is found between expected returns of large firms and fund discounts. Wang (2001) suggests that measures of market sentiment can be used to forecast stock returns and their volatility. Brown and Cliff $(2004,2005)$ use survey data as a measure of investor sentiment to forecast market returns. Schmeling (2009) adopts consumer confidence as a proxy for individual investor sentiment. Baker and Stein (2004)

\footnotetext{
* Department of Economics and Lau Chor Tak Institute of Global Economics and Finance, The Chinese University of Hong Kong, Hong Kong.

$\dagger$ Department of Economics, Hong Kong Baptist University, Hong Kong.

${ }^{\ddagger}$ Department of Finance and Big Data Research Center, Asia University, Taiwan Department of Economics and Finance, Hang Seng Management College, Hong Kong. Email: wong@asia.edu.tw Acknowledgment: The authors are grateful to Wasim Qazi and Imtiaz Arif, the Editors and anonymous referees for substantive comments that have significantly improved this manuscript. We would like to thank Margaret Loo, Min Chen, Alex Yiu and Sophia Lok for able research assistance. The third author would also like to thank Robert B. Miller and Howard E. Thompson for their continuous guidance and encouragement. The research is partially supported by The Chinese University of Hong Kong, Hong Kong Baptist University, Asia University, Hang Seng Management College, Lingnan University, the Research Grants Council (RGC) of Hong Kong (projects Nos. 12502814 and 12500915), and Ministry of Science and Technology (MOST), R.O.C. All the remaining errors are ours.
} 
propose that liquidity, such as market turnover, can serve as a sentiment indicator. Baker and Wurgler $(2006,2007)$ develop a composite index of sentiment based on the first principal component of six variables. More recently, Chen, Chong, and Duan (2010); Chen, Chong, and She (2014) develop a market sentiment index for the Hong Kong and Chinese stock markets respectively. The sentiment measure in (Chen et al., 2010) do not account for the Chinese stock market reform and its impact on the stock market of Hong Kong. Over the past decade, the Chinese stock market has grown rapidly in terms of turnover and market capitalization. The capitalization of the Chinese stock market increased by 798\% between 2002 to 2012, ranking second largest among G20 countries behind Indonesia. Qiao, Chiang, and Wong (2008) studied the co-integrating relationship among the A-share markets and B-share markets in Shanghai and Shenzhen, as well as the Hong Kong stock exchange. It is found the existence of unidirectional volatility spillover effects between the two A-share markets and the Hong Kong Stock Exchange. Further investigation revealed that the mainland government's easing of regulations on domestic residents' purchasing of B-shares increased the market integration process of the Hong Kong market with the A-share stock markets. Zhou, Zhang, and Zhang (2012) show that since 2005, the volatility of the Chinese market has had a significant positive impact on world equity markets, including that of Hong Kong. The economies of Hong Kong and China started to integrated especially after 2003, where the central government of China implemented a number of measures to boost the economy of Hong Kong for it to recover from the outbreak of the severe acute respiratory syndrome (SARS). Also, due to the policy of internationalization of Renminbi (RMB) of China, Hong Kong has become a RMB offshore center in recent years. Hong Kong now possesses a RMB bond market outside Mainland China. China's expanding trade also results in a wider RMB deposit base in Hong Kong, all of which havefostered the integration of the two markets over the past decade. In Novenmeber 2014, the Shanghai-Hong Kong Stock Connect was launched. It is a pilot programme that links the stock markets in Hong Kong and Shanghai. Under the programme, investors in China and Hong Kong can trade and settle shares listed on the other market via the home market's exchange and clearing house. In December 2016, the Shenzhen-Hong Kong stock connect was also launched. As a result, the interaction between the Chinese and Hong Kong markets is increasingly prominent.

In light of the increasing integration between China and Hong Kong, this paper improves the sentiment index of Chen et al. (2010) by developing a new market sentiment index for the Hong Kong stock market by including the CSI 300 index, which represents the performance of the Chinese equity market, together with other seven proxies that are already used in Chen et al. (2010). We focus on the post-SOE reform and post-2008 financial crisis periods, which are not covered by Chen et al. (2010). We also use our results to develop a new trading rule which is shown to be profitable.

The rest of the paper presents the data and methodology of our study and reports the estimation result. After obtaining the market sentiment index, we apply the multivariate threshold model of Tsay (1998) to capture the movement of the stock index in market states. The Hansen (2000) likelihood ratio is employed to test whether there is a significant threshold effect, and the results compared with the Hang Seng Index. We also use the sentiment index as a threshold variable in a threshold regression model to classify the 
state of the Hong Kong stock market. Finally, a trading rule is developed and compared with the buy-and-hold strategy in trading rule to test the out-of-sample performance of our index. The last section presents the conclusion.

\section{Data and Methodology}

Our data is obtained from various financial sources online. Historical daily turnover and prices of the Hang Seng Index (HSI) from 1 December 2008 to 31 December 2012 are obtained from Quamnet. Data for the short-selling volume is obtained from Yahoo Finance. The daily Hong Kong Interbank Offered Rate (HIBOR) is obtained from the Hong Kong Monetary Authority. Historical data for the S\&P 500, the Nikkei 225, and the CSI 300 indices are gathered from Yahoo Finance. The stock market sentiment index is estimated using the principal-component method.

Chen et al. (2010) use the principal-component method to form a linear index with factors such as the short selling volume, market turnover, Hong Kong Interbank Offered Rate (HIBOR), relative strength index, money flow index, and the indices of foreign equity markets. In this paper, a composite measure of investor sentiment is developed by applying the PCA to the eight variables. First, we standardize the eight variables and obtain the eigenvalue and eigenvector of their covariance matrix. We then construct the sentiment index as a linear combination of the eight variables by using the eigenvector associated with the largest eigenvalue as the corresponding weight. For each time period $t$, our investor sentiment index SMTt is defined as the first principal component of the following eight factors:

$$
S M T_{t}=\alpha+\beta_{1} T R_{t}+\beta_{2} S S T_{t}+\beta_{3} R S_{t}+\beta_{4} M F_{t}+\beta_{5} H I B O R_{t}+\beta_{6} S P_{t-1}+\beta_{7} J A P_{t-1}+
$$

where,

$S M T_{t}$ is the stock market sentiment index;

$T R_{t}$ is the turnover ratio;

$S S T_{t}$ is the short-selling turnover ratio;

$R S_{t}$ is the relative strength index;

$M F_{t}$ is the money flow index;

$H I B O R_{t}$ is the Hong Kong Interbank Offered Rate;

$S P_{t}$ is the return of the S\&P 500 index;

$J A P_{t}$ is the return of the Nikkei 225 index;

$C S I_{t}$ is the return of the CSI 300 index.

The turnover ratio is included in the sentiment measurement model because it measures the stock market's trading activity. Findings concerning the relationship between turnover and stock market trend suggest that a larger turnover is usually associated with 
a price rise, whereas a small turnover is associated with a price fall. The turnover rate is defined as:

$$
T R_{t}=100(V M 10 t / V M 250 t)
$$

where VM10t is the average turnover for the past 10 trading days and VM250t is the average turnover for the past 250 trading days.

We include the number of short-selling trades as a proxy for the amount of negative information in the sentiment model. The short-selling turnover ratio is defined as the amount of short-sold shares divided by the number of shares traded in one day:

$$
S S T_{t}=\text { short }- \text { selling } \text { volume }_{t} / \text { turnover }_{t}
$$

where short-selling volume is the amount of stock shares sold short and turnover is the total amount of stock shares traded.

The RSI is used to indicate if the market is over-bought or over-sold. Here, the sum of the positive stock price difference over the past 14 days is divided by the sum of the absolute value of price change in the same period to obtain the RSI index:

$$
R S(14)_{t}=100 * \frac{\sum_{i=1}^{14}\left(P_{t-i}-P_{t-i-1}\right)}{\sum_{i=1}^{14}\left|\left(P_{t-i}-P_{t-i-1}\right)\right|}
$$

where $\left(P_{t-i}-P_{t-i-1}\right)+=P_{t-i}-P_{t-i-1}$ if $P_{t-i}-P_{t-i-1}>0$, and $=0$ otherwise.

The Money Flow Index contains information on both daily stock price and turnover. To obtain the MF, we define

$$
\text { Daily Price }=(\text { low }+ \text { high }+ \text { close }) / 3
$$

We then define the money flow as:

$$
\text { Money Flow }=\text { Daily Price } * \text { Turnover. }
$$

The money flow is defined as positive if the daily price is lower in the previous day. If the previous day's price is higher, the money flow is negative. We compute the positive money flow and negative money flow in the past 30 days. The money flow index is defined as:

$$
\begin{aligned}
& \text { MF }=100 \text { Positive Money Flow }_{30} /\left(\text { Positive Money Flow } \text { Plo }_{30}+\right. \\
& \text { NegativeMoneyFlow } \left.\text { Plo }_{30}\right)
\end{aligned}
$$

HIBOR is used here to reflect the cost of investment. K. Y. Lee (2006) shows that both the U.S. and Japanese stock markets significantly affect the Hong Kong stock market. 
To reflect these influences and the influence of the China's market, we include the daily returns of China's CSI 300, the United States' S\&P 500, and the Japanese Nikkei 225 in our sentiment measure. Their return series are defined as follows:

$$
\begin{gathered}
S P_{t}=\ln S \& P 500_{t}-\ln S \& P 500_{t-1} \\
J A P_{t}=\ln N I K K E I_{t}-\ln N I K K E I_{t-1} \\
C S I_{t}=\ln C S I 300_{t}-\ln C S I 300_{t-1}
\end{gathered}
$$

\section{Estimation}

The stock market sentiment index, denoted by SMTt, is the first principal component of the eight previously stated variables. The principal component is estimated by using the Hmisc package of the $\mathrm{R}$ statistical program. The estimation result is as follows:

$$
\begin{array}{r}
S M T_{t}=-4.77+1.98 T R_{t}-28.57 S S T_{t}+0.03 R S_{t}+0.05 M F_{t}-3.30 H I B O R_{t}+7.88 S P_{t-1}+ \\
19.96 J A P_{t-1}+11.96 C S I_{t-1}
\end{array}
$$

The estimates are obtained by converting the original estimates from the standardized model, which is estimated by applying the PCA to the standardized variables subject to the constraint that the vector of the estimates is of unit length.

Our results show that market sentiment is positively related to stock turnover, but negatively related to the short-selling activities. The RSI and MF are both positively related to SMT, while an increase in the HIBOR rate will lower sentiment in the stock market. The performance of the mainland Chinese stock market positively affects Hong Kong's stock market sentiment. Figure 1 plots the movement of the stock market sentiment index.

Figure 1

The Sentiment Index (SMT)

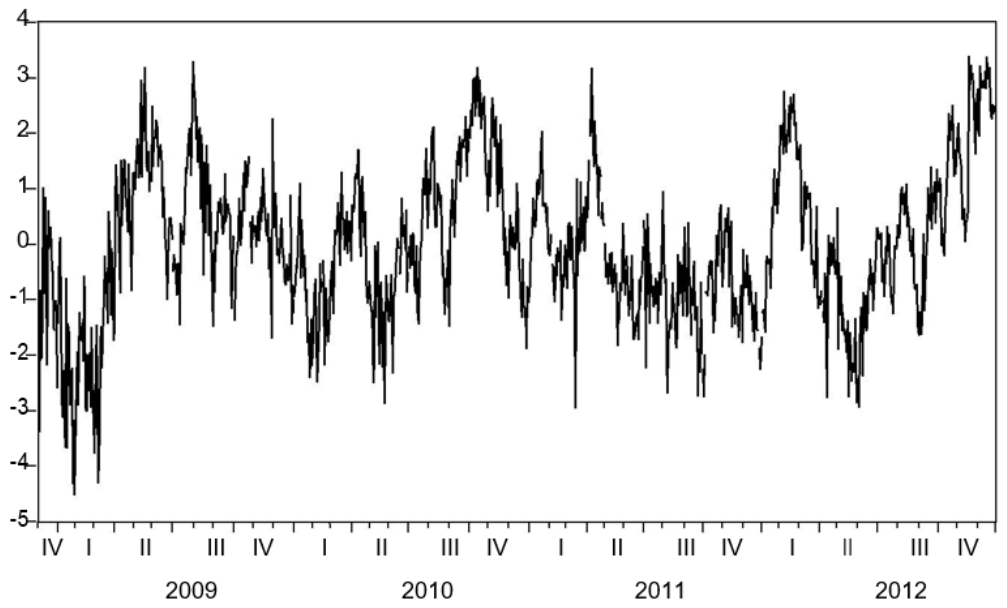


The maximum and the minimum SMT values are 3.405 and -4.533 , with most sentiment values occurring within the range of -4 to +4 . From Figure 1, we can identify three extremely low values for the sentiment index, which all occurred in early 2009 - two

occurred in January, and one in March. These coincided with the RSI also reaching its minimum value of 6.115. During these incidences, prices in the Hong Kong stock market continued to drop for several days after, resulting in a low value of the 14-day RSI.

\section{Market States of Hong Kong}

A number of previous studies have classified bull and bear states of the stock market (Pagan \& Sossounov, 2003; Lunde \& Timmermann, 2004). In this paper, we use the multivariate-threshold model (Tsay, 1998) to identify the market states. The model is as follows:

$$
y_{t}= \begin{cases}f_{1}\left(y_{t-1}, y_{t-2}, \ldots, \epsilon_{1 t} \mid \theta_{1}\right), & \text { if } S M T_{t-1} \leq \gamma_{1} \\ f_{2}\left(y_{t-1}, y_{t-2}, \ldots, \epsilon_{2 t} \mid \theta_{2}\right), & \text { if } \gamma_{1}<S M T_{t-1} \leq \gamma_{2} \\ f_{3}\left(y_{t-1}, y_{t-2}, \ldots, \epsilon_{3 t} \mid \theta_{3}\right), & \text { if } \gamma_{2}<S M T_{t-1}\end{cases}
$$

where $y_{t}$ is the stock return, defined as $y_{t}=100\left(\ln P_{t}-\ln P_{t-1}\right), f_{i}($.$) are well-defined$ functions with $f i(.) \neq f j($.$) for i \neq j, \theta i$ is a finite-dimensional parameter for any $i$, and $\epsilon_{i t}$ is the error term. We use $S M T_{t-1}$ as the threshold variable and estimate the following threshold model with two thresholds:

$$
y_{t}= \begin{cases}\alpha_{0}+\alpha_{1} y_{t-1}+\alpha_{2} y_{t-2}+\ldots+\alpha_{m} y_{t-p}+\epsilon_{1 t}, & \text { if } S M T_{t-1} \leq \gamma_{1} \\ \beta_{0}+\beta_{1} y_{t-1}+\beta_{2} y_{t-2}+\ldots+\beta_{m} y_{t-p}+\epsilon_{2 t}, & \text { if } \gamma_{1}<S M T_{t-1} \leq \gamma_{2} \\ \varphi_{0}+\varphi_{1} y_{t-1}+\varphi_{2} y_{t-2}+\ldots+\varphi_{m} y_{t-p}+\epsilon_{3 t}, & \text { if } \gamma_{2}<S M T_{t-1}\end{cases}
$$

The two threshold values of our estimation are -1.238 and 1.390, respectively. These two values can be used to identify three regimes in the state of the market. The result of the estimation is

$$
y_{t}= \begin{cases}-0.028+0.392 y_{t-1}+0.136 y_{t-2}+0.326 y_{t-3}+\epsilon_{1 t}, & \text { if } S M T_{t-1} \leq-1.238 \\ -0.045+-0.583 y_{t-1}+0.191 y_{t-2}+0.194 y_{t-3}-0.012 y_{t-4} & \text { if }-1.238<S M T_{t-1} \\ +0.017 y_{t-5}+\epsilon_{2 t}, & \leq 1.390 \\ -0.129+0.526 y_{t-1}+0.309 y_{t-2}+0.050 y_{t-3}+\epsilon_{3 t}, & \text { if } 1.390<S M T_{t-1}\end{cases}
$$

We conducted the Hansen (2000) likelihood ratio test to test for threshold effects, with the results shown in Table 1.

Table 1
\begin{tabular}{lcc} 
The Likelihood Ratio Test Result & \\
\hline Threshold value & -1.238 & 1.390 \\
Observed test value & 29.89 & 33.04 \\
Bootstrap critical value & 12.77 & 21.89 \\
\hline ** at the 5\% significance level
\end{tabular}


The observed test values are greater than their corresponding bootstrap critical values, indicating that both thresholds are significant at the $5 \%$ level. We also compare the sentiment index (SMT) with daily Hang Seng Index (HSI) from 1 December 2008 to 31 December 2012. The result is plotted in Figure 2, which 2 shows that the investor sentiment has a significant positive impact on the return of stock index futures. Periods when the sentiment index is below (above) the lower (upper) threshold value for a significant length of time are shaded. Note that when the value of the SMT is larger than the upper threshold of 1.390, the HSI displays an upward trend. If the value SMT is smaller than lower threshold of -1.238 , the HSI faces downward pressure. This suggests that our sentiment index can be used to predict the market performance.

\section{Trading Rule}

We develop a trading rule based on the sentiment index, to test whether or the index can be used to forecast the market. The developed trading rule serves to short (long) the stock when the sentiment index is larger (smaller) than 1.390. The total sample size used for prediction is $T=1010$, and we divide these samples into two groups, $p$ and $q$, where $p=810$ and $q=200$. Here we apply rolling sample $y_{t-p+1}, y_{t-p}, \ldots y_{t}$ of size $p$ to estimate threshold model discussed in Section 3, and then predict a sequence of one-step-ahead forecasts, $\left(\hat{y}_{t+1}\right)_{t=p}^{T-1}$ allowing us to have 200 forecasting results using the sentiment index.

Figure 2

The Sentiment Index and Hang Seng Index (HSI) from 2008 to 2012

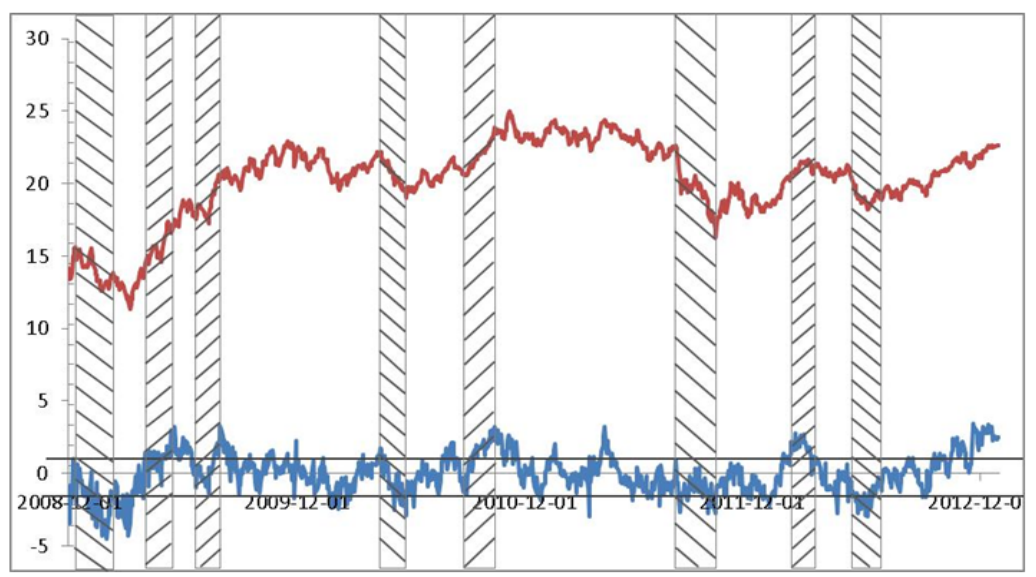

The trading strategy is to short the Hang Seng Index or S\&P/HKEx LargeCap Index when the predicted sentiment index $S M T_{t-1}$ is larger than 1.39, and long the index if the $S M T_{t-1}$ is smaller than 1.39. The HKEx LargeCap Index contains 25 stocks representing the large-cap universe for Hong Kong, covering approximately 75 percent of the total market capitalization of the Hong Kong stock market. We compare the mean of the 
forecasted return (MFTR) of these forecasting results with the buy-and-hold strategy. The MFTR is defined as:

$$
M F T R=\frac{1}{n} \sum_{t=m+1}^{\tau} \operatorname{sign}\left(1.390-S M T_{t}\right) y_{t}
$$

The MFTR of the buy-and-hold strategy is:

$$
M F T R=\frac{1}{n} \sum_{t=m+1}^{\tau} y_{t}
$$

We apply these two trading rules on HSI and S\&P/HKEx LargeCap Index, respectively. Table 2 reports the forecast results of these two strategies.

Table 2

The Average Daily Profit of Each Trading Rule

\begin{tabular}{lc}
\hline Trading rule & MFTR \\
\hline SMT (HSI) & 0.106 \\
SMT (Largecap) & 0.030 \\
Buy-and-hold (HSI) & 0.034 \\
Buy-and-hold (Largecap) & -0.010 \\
\hline
\end{tabular}

Note that for both the HSI and the S\&P/HKEx LargeCap index, the SMT-based strategy achieves higher daily profit than the buy-and-hold rule. Our result shows that for the HSI, the daily profit of the SMT-based strategy is $0.106 \%$, compared with $0.034 \%$ of the buy-and-hold trading rule. For the S\&P/HKEx LargeCap Index, the SMT-based trading strategy earns $0.030 \%$ on average, while the buy-and-hold strategy loses $0.010 \%$ in the 2008 to 2012 period.

\section{Concluding Remarks}

This paper applies the principal-component method to develop a new sentiment index for the Hong Kong stock market, one of the largest stock markets in the world, in the post-2008 financial crisis period. The components of the sentiment measure include the turnover ratio, short-selling volume, money flow, HIBOR and return of the U.S. and Japanese markets. To capture the influence of Chinese markets on the Hong Kong market, we also include the CSI 300 index in our measure. The results show that our sentiment index has a positive relationship with turnover, RSI, MF, and performance of the Chinese stock market, while it is negatively associated with short-selling volume and HIBOR. The sentiment index is used as a threshold variable in a threshold model to identify the states of the Hong Kong stock market. The result of Hansen (2000) likelihood ratio test shows that the two threshold values are significant at the 5\% level, dividing Hong Kong's stock market into three regimes. After comparing the sentiment with the Hang Seng Index (HSI), it is observed that when the sentiment index is above (below) the upper (lower) threshold, the HSI generally moves upward (downward). It is also found that the trading 
rule which shorts (longs) the HSI or S\&P/HKEx LargeCapIndex when the sentiment index is above (below) the upper threshold value can beat the buy-and-hold strategy. Since stock market sentiment depends on investors' behavior, for future work along this line, one is referred to Guo and Wong (2016); Egozcue, García, Wong, and Zitikis (2011); Lam, Liu, and Wong $(2010,2012)$ and the references therein for the behaviors of individuals with different attutidues towards risk. One is also referred to Fong, Lean, and Wong (2008); Fabozzi, Fung, Lam, and Wong (2013); Wong, Zhu, et al. (2015); Clark, Qiao, and Wong (2016) on how different types of investors make their investment decisions. 


\section{References}

Baker, M., \& Stein, J. C. (2004). Market liquidity as a sentiment indicator. Journal of Financial Markets, 7(3), 271-299.

Baker, M., \& Wurgler, J. (2006). Investor sentiment and the cross-section of stock returns. The Journal of Finance, 61(4), 1645-1680.

Baker, M., \& Wurgler, J. (2007). Investor sentiment in the stock market. The Journal of Economic Perspectives, 21(2), 129-151.

Brown, G. W., \& Cliff, M. T. (2004). Investor sentiment and the near-term stock market. Journal of Empirical Finance, 11(1), 1-27.

Brown, G. W., \& Cliff, M. T. (2005). Investor sentiment and asset valuation. The Journal of Business, 78(2), 405-440.

Chen, H., Chong, T. T.-L., \& Duan, X. (2010). A principal-component approach to measuring investor sentiment. Quantitative Finance, 10(4), 339-347.

Chen, H., Chong, T. T. L., \& She, Y. (2014). A principal component approach to measuring investor sentiment in China. Quantitative Finance, 14(4), 573-579.

Clark, E., Qiao, Z., \& Wong, W.-K. (2016). Theories of risk: Testing investor behavior on the Taiwan stock and stock index futures markets. Economic Inquiry, 54(2), 907-924.

Egozcue, M., García, L. F., Wong, W.-K., \& Zitikis, R. (2011). Do investors like to diversify? A study of Markowitz preferences. European Journal of Operational Research, 215(1), 188-193.

Fabozzi, F. J., Fung, C.-Y., Lam, K., \& Wong, W.-K. (2013). Market overreaction and underreaction: Tests of the directional and magnitude effects. Applied Financial Economics, 23(18), 1469-1482.

Fong, W. M., Lean, H. H., \& Wong, W. K. (2008). Stochastic dominance and behavior towards risk: The market for internet stocks. Journal of Economic Behavior E Organization, 68(1), 194-208.

Guo, X., \& Wong, W.-K. (2016). Multivariate stochastic dominance for risk averters and risk seekers. RAIRO-Operations Research, 50(3), 575-586.

Hansen, B. E. (2000). Sample splitting and threshold estimation. Econometrica, 68(3), 575-603.

Lam, K., Liu, T., \& Wong, W.-K. (2010). A pseudo-Bayesian model in financial decision making with implications to market volatility, under-and overreaction. European Journal of Operational Research, 203(1), 166-175.

Lam, K., Liu, T., \& Wong, W.-K. (2012). A new pseudo-bayesian model with implications for financial anomalies and investors' behavior. Journal of Behavioral Finance, 13(2), 93-107.

Lee, C., Shleifer, A., \& Thaler, R. H. (1991). Investor sentiment and the closed-end fund puzzle. The Journal of Finance, 46(1), 75-109.

Lee, K. Y. (2006). The contemporaneous interactions between the US, Japan, and Hong Kong stock markets. Economics Letters, 90(1), 21-27.

Lunde, A., \& Timmermann, A. (2004). Duration dependence in stock prices: An analysis of bull and bear markets. Journal of Business E Economic Statistics, 22(3), 253-273. 
Neal, R., \& Wheatley, S. M. (1998). Do measures of investor sentiment predict returns? Journal of Financial and Quantitative Analysis, 33(4), 523-547.

Pagan, A. R., \& Sossounov, K. A. (2003). A simple framework for analysing bull and bear markets. Journal of Applied Econometrics, 18(1), 23-46.

Qiao, Z., Chiang, T. C., \& Wong, W.-K. (2008). Long-run equilibrium, short-term adjustment, and spillover effects across Chinese segmented stock markets and the Hong Kong stock market. Journal of International Financial Markets, Institutions and Money, 18(5), 425-437.

Schmeling, M. (2009). Investor sentiment and stock returns: Some international evidence. Journal of Empirical Finance, 16(3), 394-408.

Tsay, R. S. (1998). Testing and modeling multivariate threshold models. Journal of the American Statistical Association, 93(443), 1188-1202.

Wang, C. (2001). Investor sentiment and return predictability in agricultural futures markets. Journal of Futures Markets, 21(10), 929-952.

Wong, W.-K., Zhu, Z., et al. (2015). Is gold different for risk-averse and risk-seeking investors? An empirical analysis of the Shanghai gold exchange. Economic Modelling, $50,200-211$.

Zhou, X., Zhang, W., \& Zhang, J. (2012). Volatility spillovers between the Chinese and world equity markets. Pacific-Basin Finance Journal, 20(2), 247-270. 